\title{
Efeito da massagem do úbere ao final da ordenha no leite residual e na ocorrência de mastite em vacas leiteiras
}

\author{
Marcela Cristina Agustini Carneiro da Silveira* \\ Luiz Carlos Pinheiro Machado Filho \\ Maria José Hötzel \\ Laboratório de Etologia Aplicada, Departamento de Zootecnia e Desenvolvimento Rural \\ Universidade Federal de Santa Catarina; Rodovia Admar Gonzaga, 1346 \\ CEP 88.034-001, Florianópolis - SC, Brasil \\ Autor para correspondência \\ marcelasilveira@uft.edu.br
}

Submetido em 17/06/2008

Aceito para publicação em 15/09/2008

\section{Resumo}

O leite residual (LR) pós-ordenha é um importante fator predisponente de mastite. Neste estudo foi testada a hipótese de que a massagem do úbere ao final da ordenha pode reduzir o LR e a incidência de mastite. Para tanto foram realizados dois experimentos, o experimento 1 foi realizado numa fazenda experimental com 10 vacas $(6.200 \mathrm{~kg} / \mathrm{lactação)} \mathrm{e} \mathrm{o} \mathrm{experimento} 2$ em fazenda comercial com 52 vacas (4.480kg/lactação). Em ambos os experimentos as vacas foram pareadas por número de partos, estágio de lactação e produtividade e aleatoriamente destinadas a um dos tratamentos: com massagem ou sem massagem do úbere, em duas etapas num desenho "cross-over". A produção de leite individual de cada vaca foi medida. O leite residual foi coletado e medido 2 min após aplicação de ocitocina intravenosa. Foi usado o Califórnia Mastite Teste (CMT) para detectar mastite subclínica. Em ambos os experimentos a massagem não teve efeito na produção de leite (experimento $1, \mathrm{p}>0,41, \mathrm{n}=10$; e experimento $2, \mathrm{p}>0,46, \mathrm{n}=12$ ), nem no LR (experimento $1,1,78 \pm 0,45 \mathrm{~kg}, \mathrm{n}=10$; experimento $2,2,42 \pm 0,32 \mathrm{~kg}, \mathrm{n}=12$ ), e nem na incidência de mastite (experimento 2, qui-quadrado, $\mathrm{p}>0,68$, $\mathrm{n}=26$ ). Concluiu-se que, nas condições do experimento, a massagem no úbere não teve efeito no LR e nem na incidência de mastite.

Unitermos: leite residual, mastite, bem-estar, ordenha, vaca leiteira

\section{Abstract}

Effect of udder massage at the end of milking on residual milk and mastitis occurrence in dairy cows. Residual milk (RM) after milking is an important factor that can predispose cows to mastitis. In this study, the hypothesis that udder massage at the end of milking may reduce RM and the incidence of mastitis was tested in two experiments. Experiment 1 was conducted on an experimental farm with ten lactating cows $(6,200 \mathrm{~kg} /$ lactation) and experiment 2 was carried out on a commercial farm with 52 lactating cows (4,480kg/lactation). In both experiments the cows were paired by parity, stage of lactation and productivity, and they were randomly assigned to one of the treatments: massage or no massage of the udder at the end of milking, in two periods in a crossover design. The individual milk production of each cow was measured. Residual milk was collected and measured $2 \mathrm{~min}$ after an oxitocin application. California Mastitis Test was used to detect the occurrence 
of subclinical mastitis. In neither of the experiments did udder massage have any effect on milk production (experiment $1 \mathrm{p}>0.41, \mathrm{n}=10$ and experiment $2 \mathrm{p}>0.46, \mathrm{n}=12$ ), on $\mathrm{RM}$ (experiment $1,1.78 \pm 0.45 \mathrm{~kg}, \mathrm{n}=$ 10 ; experiment $2,2.42 \pm 0.32 \mathrm{~kg}, \mathrm{n}=12$ ), or on mastitis incidence (experiment 2, chi-square; $\mathrm{DF}=1 ; \mathrm{p}>0.68$, $\mathrm{n}=26$ ). We conclude that udder massage at the end of milking has no effect on RM and does not affect mastitis incidence, at least under the conditions used in these experiments.

Key words: residual milk, mastitis, welfare, management, milking

\section{Introdução}

A mastite é um processo inflamatório da glândula mamária, que causa perdas na quantidade e qualidade de leite, afeta o bem-estar animal e aumenta a necessidade do uso de antibióticos. Ao aumentar o uso de antibióticos aumenta o risco da presença de seus resíduos no leite de consumo (Raia Junior, 2001; Tetzner et al., 2005) o que contribui com a contaminação do ambiente, da cadeia alimentar e com a resistência dos microorganismos a drogas de importância para a saúde humana (Rollin, 2001).

A mastite está entre as principais enfermidades que afetam o gado leiteiro, levando em conta o impacto das diversas doenças na produtividade, risco de zoonose, comércio internacional e bem-estar animal (Wells et al., 1998). Além de causar perdas diretas na produção leiteira, leva a um aumento do custo de produção pelos gastos com serviços e produtos veterinários.

Segundo Nuñez et al. (2001), estima-se que $70 \%$ das perdas devido à mastite são relacionadas à diminuição da produção de leite, $14 \%$ devido a saída prematura dos animais do rebanho, $7 \%$ devido ao descarte do leite e $8 \%$ devido a despesas veterinárias. Estima-se que no Brasil este problema leve a perdas anuais superiores a U $\$ 300$ por vaca nos rebanhos afetados (Costa et al., 1999), ou a perda de 2,8 bilhões de litros de leite por ano (Fonseca e Santos, 2000). Considerando o preço médio do leite pago ao produtor no primeiro semestre de 2007 em Santa Catarina, de R $\$ 0,45 / \mathrm{kg}$ (Marcondes, 2007), pode-se projetar perdas superiores a um bilhão de reais por ano somente devido à mastite.

A mastite pode ser caracterizada como clínica ou subclínica e ambos tipos levam a perdas na quantidade e qualidade do leite (Harmon, 1994). A mastite é causada principalmente por bactérias que estão normalmente presentes no ambiente. Considerando- se que é impraticável - e mesmo desaconselhável - esterilizar o ambiente em que os animais estão, a eliminação dos fatores predisponentes à mastite ganha importância na prevenção do problema.

Dentre os fatores predisponentes à mastite estão a alta produção leiteira, a ordem de parição, o estágio de lactação, a pré-disposição genética, a higiene das instalações e da ordenha, a época do ano, os sistemas de produção e o uso de somatotropina bovina recombinante (Harmon, 1994; Gröhn et al., 1995; Barkema et al., 1999; Health Canada, 1999; Heringstad et al., 2000; Fleischer et al., 2001). A maioria destes fatores altera também a quantidade de leite residual no úbere.

O leite residual foi relatado como um fator predisponente da mastite (Gröhn et al., 1995; Rosenfeld, 2005). Além disso reduz a secreção de leite (Carruthers et al., 1993; Knight et al., 1994; Bruckmaier e Blum, 1998) e conseqüentemente a produção leiteira (Schmidt et al., 1988). A quantidade do leite residual é de aproximadamente $15 \%$ do total presente no úbere (Schmidt et al., 1988). Vários fatores influenciam a quantidade de leite residual após a ordenha, como a produção leiteira (Gröhn et al., 1995), o estágio de lactação (Knight et al., 1994), a idade (Schmidt et al., 1988), o estresse durante a ordenha (Rushen et al., 2001), a qualidade das relações humano-animais (Rushen et al., 1999), a hierarquia social (Yunes, 2001) e o tipo de ordenha, manual ou mecânica (Schmidt et al., 1988; Gorewit et al., 1992; Bar-Peled et al., 1995).

A retirada do leite residual pode ser feita com o uso de ocitocina exógena. Entretanto, o seu uso fica restrito a fins de pesquisa, pois se utilizado frequentemente esse hormônio pode causar efeitos colaterais, inclusive mastite (Hillerton e Semmens, 1999). A redução do leite residual é eficientemente feita pelo bezerro durante a mamada. Os bezerros normalmente cabeceiam a base do úbere durante a mamada, o que ocorre em maior 
freqüência no início e no fim do evento de mamada (Lidfors et al., 1994; Haley et al., 1998). A freqüência de cabeçadas aumenta quando a vaca é ordenhada antes de amamentar o bezerro (De Passillé et al., 1996), o que deve estar relacionado à diminuição da disponibilidade de leite no úbere. Haley et al. (1998) controlaram o aporte de leite em teteiras artificiais e observaram que o comportamento de cabecear aumenta em função da diminuição ou parada do fluxo de leite. Em outro estudo, quando a vaca era tratada com ocitocina durante o evento de amamentação, levando a um fluxo constante de leite, a freqüência de cabeçadas por parte do bezerro era baixa (Mayntz e Costa, 1998). Estes estudos sugerem que o comportamento do bezerro de cabecear o úbere estimula a secreção de ocitocina e conseqüentemente a ejeção de leite dos alvéolos.

Skrzypek et al. (2004) observaram que a massagem do ubere na ordenha foi associada com a diminuição de células somáticas. $\mathrm{O}$ uso da massagem como rotina obrigatória antes de cada ordenha tem sido sugerido, pois estimularia a liberação de ocitocina (Bruckmaier e Blum, 1998). A falta da massagem pode causar distúrbios no curso da ordenha, resultando em aumento dos danos mecânicos do úbere e consequentemente, infecções. A massagem atuaria estimulando a liberação de ocitocina e ejeção de leite alveolar, e também atuaria por efeito mecânico, fazendo pressão na parte alta do úbere e proporcionando a descida do leite. Desta forma, se reduziria o leite residual e, por consequiência, a incidência de mastite. Neste trabalho testamos o efeito da massagem manual do úbere ao final da ordenha na quantidade de leite residual e na incidência de mastite.

\section{Material e Métodos}

Esta pesquisa foi dividida em dois experimentos. O experimento 1 foi realizado na unidade de gado leiteiro do CETRE - EPAGRI, em Florianópolis, SC, com um grupo de 10 vacas da raça Holandês. As vacas eram ordenhadas duas vezes ao dia (6:00 e 16:30) e tinham média de produção leiteira de $6200 \mathrm{~kg} / \mathrm{lactação.} \mathrm{Eram}$ criadas em sistema de semi-confinamento, ficando em estabulação livre durante o dia entre as duas ordenhas e o restante do tempo em sistema de pastoreio. No estábulo eram alimentadas no cocho com silagem de milho e $5 \mathrm{~kg}$ de concentrado por vaca/dia. Elas foram pareadas por número de partos (de 1 a 5), estágio de lactação (até 100 dias, entre 101 e 200 dias a de 200 a 300 dias) e nível de produção, e aleatoriamente designadas para um dos tratamentos: com massagem e sem massagem do úbere ao final da ordenha. No tratamento com massagem o ordenhador, ao final de cada ordenha e antes de retirar as teteiras, fazia uma massagem vigorosa nos quatro quartos do úbere, comprimindo-os para dentro e para baixo, por dez segundos. O tratamento controle não tinha massagem.

As variáveis observadas foram a produção de leite e a quantidade de leite residual. O leite coletado até a retirada das teteiras, quando o fluxo de leite na ordenhadeira era quase nulo, representou a produção de leite. Para a retirada do leite residual foi feita uma única aplicação de 20 UI de ocitocina na veia mediana caudal, 2 minutos após a retirada das teteiras. O leite residual foi, então, extraído por ordenha mecânica com acoplamento das teteiras 1 minuto após a injeção de ocitocina. Este procedimento foi realizado em duas ordenhas com um intervalo de um dia entre as medidas, cinco dias após o início dos tratamentos. Os tratamentos foram então invertidos em um delineamento do tipo cross-over, em que o mesmo animal passa pelos dois tratamentos. Após três dias de tratamento, foi medida novamente a produção de leite e o leite residual.

O experimento 2 foi desenvolvido na unidade de produção de leite da COOPERUNIÃO, no município de Dioníso Cerqueira, SC. Foram utilizadas 52 vacas da raça Holandês com produção leiteira média de $4480 \mathrm{~kg} /$ lactação. As vacas estavam em sistema de pastoreio, eram ordenhadas duas vezes ao dia (3:30 e 14:30), e recebiam $2 \mathrm{~kg}$ de ração concentrada/vaca/dia. As vacas foram pareadas por número de partos (variaram entre 1 e 5 partos), estágio de lactação (até 100 dias, 101 a 200 dias e de 200 a 300 dias de lactação), produção de leite, e aleatoriamente designadas para um dos tratamentos: com massagem ou sem massagem do úbere ao final da ordenha, conforme descrito para o experimento 1 .

Durante os 60 dias do experimento foram medidas, semanalmente, a produção individual de leite e a ocorrência de mastite subclínica através do Califórnia 
Mastite Teste - CMT. O CMT foi realizado classificandose a reação inflamatória de acordo com os escores: 1 - negativo, 2 - reação suspeita e 3 - positivo, de acordo com a consistência do gel, formado pela adição do reagente ao leite. O CMT foi escolhido por fornecer resultados imediatos, ser de baixo custo e ter correlação positiva com a inflamação. Brito et al. (1997) e Barbosa et al. (2002) encontraram sensibilidade de $82 \%$ do CMT em relação à contagem de células somáticas, considerando-se como reações positivas a ocorrência de mastite subclínica. Neste experimento um dos ordenhadores, cego para os tratamentos aos quais as vacas foram alocadas, foi treinado para a leitura dos testes.

Após os dois meses de tratamento, o leite residual foi medido durante dois dias, com um dia de intervalo, conforme descrito para o experimento 1 . Adicionalmente, um grupo de 6 pares de vacas ( 6 de cada tratamento) foi aleatoriamente selecionado e os tratamentos foram invertidos. Após uma semana de tratamento trocado foram medidas por dois dias a produção de leite e o leite residual (após a aplicação de ocitocina) dessas vacas, conforme descrito para o experimento 1 .

Foi realizada análise de variância para as variáveis Leite Residual e Leite Total, para ambos experimentos, utilizando-se o procedimento GLM em SAS (1985). Além do efeito de tratamento, o efeito de número de partos (1 a 5) e estágio de lactação (100 dias, 101 a 200 e 201 a 300 dias) foram incluídos no modelo. No experimento 2 , a variável incidência de mastite foi analisada pelo teste do Qui-quadrado. Estes experimentos foram aprovados pelo Comitê de Ética no Uso de Animais (CEUA) da UFSC.

\section{Resultados}

Não registramos efeito do tratamento massagem do úbere ao final da ordenha na produção de leite das vacas ou no leite residual no experimento 1 (respectivamente $18,1 \mathrm{~kg} ; \mathrm{P}>0,41$ e $1,78 \pm 0,45 \mathrm{~kg} ; \mathrm{P}>0,88)$, e nem no experimento 2 (respectivamente 12,7; $\mathrm{P}>0,46$ e 2,42 \pm $0,32 \mathrm{~kg} ; \mathrm{P}>0,51)$. No experimento 2 , não houve efeito da massagem do úbere na incidência de mastite nas vacas (Qui-quadrado; $d f=1 ; p>0,68$ ). Durante o período estudado a incidência semanal de mastite foi de 1,5 \pm 0,47 casos entre as vacas que receberam massagem e $2 \pm 0,42$ casos entre as vacas que não receberam massagem (Figura 1). Em nenhum dos experimentos houve efeito do estágio de lactação das vacas, ou da ordem de parição, na quantidade de leite residual ou na incidência de mastite.

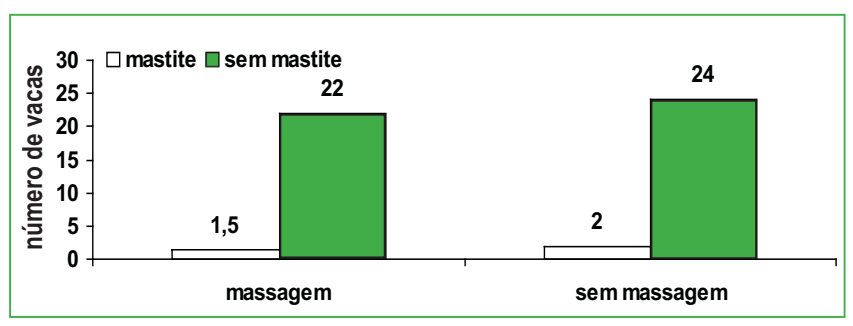

FIGURA 1: Média semanal de ocorrência de mastite segundo tratamento durante o período de 3 meses do experimento 2 (Qui-quadrado; $\mathrm{DF}=1 ; \mathrm{P}>0.68$ ).

\section{Discussão}

Esperava-se que o efeito tátil e mecânico da massagem estimulasse a liberação e a ação da ocitocina endógena (Bruckmaier e Blum, 1998), e conseqüentemente a descida do leite restante ao final da ordenha. Isto levaria a uma menor quantidade de leite residual nas vacas do grupo que recebeu massagem de úbere, e talvez a uma maior produção de leite. Neste experimento, entretanto, isso não ocorreu. A incidência de mastite entre os dois tratamentos também não foi diferente, uma vez que os fatores ambientais e genéticos foram controlados e o leite residual, uma das principais causas predisponentes à mastite (Gröhn et al., 1995), não foi alterado pela massagem.

Uma quantidade de leite residual equivalente a até $15 \%$ do total do leite ordenhado, é considerado normal (Schmidt et al., 1988). Portanto, os resultados para leite residual encontrada neste trabalho estão dentro da variação esperada e encontrada na literatura. As vacas com produção em torno de $18 \mathrm{~kg}$ de leite/dia, apresentaram $1,78 \mathrm{~kg}$ de leite residual, e as de $13 \mathrm{~kg} / \mathrm{dia}$, $2,42 \mathrm{~kg}$. Knight et al. (1994) encontraram variação de leite residual de 0,8 a $6,98 \mathrm{~kg}$ em vacas leiteiras de $27,5 \mathrm{~kg}$ no pico de lactação ( 7 semanas pós parto); já para vacas de $13,15 \mathrm{~kg}$ no final da lactação (28 semanas pós parto) a variação foi de 0,88 a $2,02 \mathrm{~kg}$. 
O aumento no leite residual reduz a produção leiteira. Schmidt e Van Vleck (1975) demonstraram essa correlação quando identificaram que quantidades entre 1,8 e 3,6kg de leite residual reduziram a produção leiteira entre 4 e $10 \%$. Estresse, quebra de rotina ou tratamento aversivo podem aumentar o leite residual, e assim reduzir a produção de leite. Vacas de produção média de $23 \mathrm{~kg} /$ dia de leite/dia podem dobrar a quantidade de leite residual quando a ordenha era feita em um ambiente desconhecido (Rushen et al., 2001). Num rebanho cuja produção média era de $22 \mathrm{~kg} /$ dia, imposição de estresse aumentou o leite residual de 2,1 para 3,6kg/vaca (Rushen et al., 1999). Tratamento aversivo por parte de seres humanos também pode aumentar o leite residual (Rushen et al., 1999) e pode causar diminuição da produção leiteira (Breuer et al., 2000).

Nem o estágio de lactação e nem a ordem de parição das vacas influenciaram a incidência de mastite ou o leite residual em nenhum dos dois experimentos. Em contraste, Knight et al. (1994) encontraram que as vacas que estão no primeiro terço de lactação têm mais leite residual do que aquelas no último terço de lactação, tanto uma hora após a ordenha quanto após doze horas. Vacas com maior número de parições, e, portanto mais velhas, retêm mais leite após a ordenha (Schmidt et al., 1988) e geralmente são dominantes dentro do grupo. Vacas dominantes retém mais leite residual do que subordinadas (Yunes, 2001).

Em síntese, no presente trabalho não houve efeito da massagem no úbere ao final da ordenha na produção de leite, no leite residual e nem a ocorrência de mastite. Da mesma forma, nenhum dos fatores estudados (estágio de lactação ou ordem de parição) influenciou a quantidade de leite residual ou a incidência de mastite.

\section{Agradecimentos}

À equipe do LETA pelo apoio, em particular à Maria C. Yunes, Cícero T. Berton e Givanildo R. Furlanetto. Ao CETRE/EPAGRI e à COOPERUNIAO por permitirem e ajudarem no desenvolvimento do experimento. Ao CNPq pelo apoio com a bolsa da pesquisadora visitante Maria José Hotzel. Ao Programa de Pós-graduação em Agroecossistemas e ao Departamento de Zootecnia e Desenvolvimento Rural (UFSC) pela contribuição financeira que viabilizou o desenvolvimento do trabalho.

\section{Referências}

Barbosa, C. P.; Benedetti, E.; Ribeiro, S. C. A.; Guimarães, E. C. 2002. Relação entre contagem de células somáticas (CCS) e os resultados do "Califórnia Mastitis Test" (CMT) no diagnóstico de mastite bovina. Bioscience Journal, 18 (1): 93-102.

Barkema, H. W.; Schukken Y. H.; Lam, T. J. G. M.; Beiboer, M. L.; Benedictus, G.; Brand, A. 1999. Management practices associated with the incidence rate of clinical mastitis. Journal Dairy of Science, 82 (8): 1643-1654.

Bar-Peled, U.; Maltz, E.; Bruckental, I.; Folman, Y.; Kali, Y.; Gacitua, H.; Lehrer, A. R.; Knight, C. H.; Robinzon, B.; Voet, H. 1995. Relationship between frequent milking or suckling in early lactation and milk production of high producing dairy cows. Journal Dairy of Science, 78 (1): 2726-2736.

Breuer, K.; Hemsworth P. H.; Barnett J. L.; Matthews L. R.; Coleman G. J. 2000. Behavioural response to humans and the productivity of commercial dairy cows. Applied Animal Behaviour Science, 66 (4): 273-288.

Brito, J. R. F.; Caldeira, G. A. V.; Verneque, R. S.; Brito, M. A. V. P. 1997. Sensibilidade e especificidade do "California Mastitis Test" como recurso diagnóstico da mastite subclínica em relação à contagem de células somáticas. Pesquisa Veterinária Brasileira, 17 (2): 49-53.

Bruckmaier, R. M.; Blum, J. W. 1998. Oxytocin release and milk removal in ruminants. Journal Dairy of Science, 81 (1): 939-949.

Carruthers, V. R.; Davis, S. R.; Copeman, P. J. A. 1993. Effects of oxytocin, machine stripping and milking rate on production loss of cows milked once a day. Journal of Dairy Research, 60 (1): 13-18.

Costa, E. O.; Ribeiro, A. R.; Watanabe, E. T.; Silva, J. A. B.; Gario J. R. F.; Benites, N. R.; Hotiuti, A. M. 1999. Mastite subclínica: Prejuízos causados e os custos de prevenção em propriedades leiteiras. Revista Napgama, 2 (2): 16-20.

De Passillé, A. M.; Richer, G.; Morrissette J.; Rushen, J. 1996. Quantity of milk in the udder, the level of hunger, and sucking behaviour of the nursing calf. Proceedings of the 30th International Congress of the International Society for Applied Ethology, 30: 58 .

Fleischer, P.; Metzner, M.; Beyerbach, M.; Hoedemaker, M.; Klee, W. 2001. The relationship between milk yield and the incidence of some diseases in dairy cows. Journal of Dairy Science, 84 (9): 2025-2035.

Fonseca, L. F. L.; Santos, M. V. 2000. Qualidade do leite e controle de mastite. Lemos Editorial, São Paulo, Brasil, 175pp.

Gorewit, R. C.; Svennersten, K.; Butler, W. R.; Uvnasmoberg, K. 1992. Endocrine responses in cows milked by hand and machine. Journal of Dairy Science, 75 (1): 443-448.

Gröhn, Y. T.; Eicker, S. W.; Hertl, J. A. 1995. The association between previous 305-day milk yield and disease in New York State dairy cows. Journal of Dairy Science, 78 (8): 1693-1702. 
Haley, D. B.; Rushen, J.; Duncan, I. J. H.; Widowski, T. M.; De Passillé, A. M. 1998. Butting by calves, Bos taurus, and rate of milk flow. Animal Behaviour, 56 (1): 1545-1551.

Harmon, R. J. 1994. Physiology of mastitis and factors affecting somatic cell counts Journal of Dairy Science, 77 (1): 2103-2112.

Health Canada. 1999. Health Canada rejects bovine growth hormone in Canada. Disponível em $<$ http://www.hcc.gc.ca/english/ media/releases/1999/99. > . Acesso em 15 de março de 2002

Heringstad, B.; Klemetsdal, G.; Ruane, J. 2000. Selection for mastitis resistance in dairy cattle: a review with focus on the situation in the nordic countries. Livestock Production Science, 64 (2-3): 95-106.

Hillerton, J. E.; Semmens, J. E. 1999. Comparison of treatment of mastitis by oxytocin or antibiotics following detection according to changes in milk electrical conductivity prior to visible signs. Journal of Dairy Science, 82 (1): 93-98.

Knight, C. H.; Hirst, D.; Dewhurst, R. J. 1994. Milk accumulation and distribution in the bovine udder during the interval between milkings. Journal of Dairy Research, 61: 67-177.

Lidfors, L. M.; Jensen, P.; Algers, B. 1994. Suckling in free-ranging beef-cattle - temporal patterning of suckling bouts and effects of age and sex. Ethology, 98: 321-332.

Marcondes, T. 2007. Síntese da agricultura catarinense: Desempenho da produção animal, leite. Disponível em $<$ http://cepa.epagri.sc.gov.br/Publicacoes/ sintese 2007/Leite_2007.pdf $>$. Acesso em 22 de maio de 2008.

Mayntz, M.; Costa, R. 1998. Effect of pharmacologically induced changes in milk ejection on suckling in Bos taurus. Physiology \& Behavior, 65 (1): 151-156.

Nuñez, B. S. M.; Cañon, H.; Iraguen, D.; Espinoza, S.; Lillo, J. 2001. Depletion study of trimethoprin and sulphadiazine in milk and its relationship with mastitis phatogenic bacteria strains minimum inhibitory concentrations (MICs) in dairy cows. Journal of Veterinary Pharmacology and Therapeutics, 24 (1): 83-88.

Raia Junior, R. B. 2001. Influência da mastite na ocorrência de resíduos antimicrobianos no leite. Dissertação de Mestrado, Universidade de São Paulo, Brasil, 78pp.
Rollin, B. 2001. Ethics, science, and antimicrobial resistance. Journal of Agricultural \& Environmental Ethics, 14 (1): 29-37.

Rosenfeld, A. M. F. 2005. Retenção láctea: Fator etiológico predisponente às inflamações da glândula mamária de bovinos. Características fisico-químicas, celulares e microbiológicas do leite. Dissertação de Mestrado, Universidade de São Paulo, Brasil, $129 \mathrm{pp}$.

Rushen, J.; De Passille, A. M. B.; Munksgaard, L. 1999. Fear of people by cows and effects on milk yield, behavior, and heart rate at milking. Journal of Dairy Science, 82 (4): 720-727.

Rushen, J.; Munksgaard, L.; Marnet, P. G.; De Passille, A. M. 2001. Human contact and the effects of acute stress on cows at milking. Applied Animal Behaviour Science, 73 (1): 1-14.

SAS. 1985. SAS User's Guide: statistics. SAS Institute, Cary, USA, 956pp.

Schmidt, G. H.; Van Vleck, L. D. 1975. Bases cientificas de la produccion lechera. Editorial Acribia, Zaragoza, España, 583pp.

Schmidt, G. H.; Van Vleck, L. D.; Hutjens, M. F. 1988. Principles of Dairy Science. Prentice Hall, New Jersey, USA, 466pp.

Skrzypek, R.; Wójtowski, J.; Fahr, R. D. 2004. Factors affecting somatic cell count in cow bulk tank milk - A case study from Poland. Journal of Veterinary Medicine Series A, 51 (1): 127-131.

Tetzner, T. A. D.; Benedetti, E.; Guimarães, E. C.; Peres, R. F. G. 2005. Prevalência de resíduos de antibióticos em amostras de leite cru na região de Triângulo Mineiro, MG. Revista Higiene Alimentar, 19 (130): 69-72.

Wells, S. J.; Ott, S. L.; Seitzinger, A. H. 1998. Key health issues for dairy cattle - new and old. Journal of Dairy Science, 81: 30293035 .

Yunes, M. C. 2001. Efeito da hierarquia social em vacas leiteiras em aspectos da produção, da reprodução e da interação humano animal. Dissertação de Mestrado, Universidade Federal de Santa Catarina, Brasil, 65pp. 